\title{
Estimation of residual carrying capacity and restoration of the historic reinforced concrete shells and frames erected in Estonia
}

\author{
H. Onton \\ Department of Structural Design, \\ Tallinn University of Technology, Estonia
}

\begin{abstract}
The purpose of the research work was to examine and analyze the technical situation and to work out a restoration solution for the hydroplane hangars reinforced concrete shells and frames erected in Estonia.

The hydroplane hangars were designed and erected between 1915 and 1917 both in Tallinn and in Saaremaa, Estonia.

Due to the fact that from the civil engineering point of view the most important structure is the reinforced concrete roof shell of the Tallinn hangar, will this paper mainly focus on this historical building.

This large span structure consists of three spherical and seven cylindrical reinforced concrete roof shells and four two-storey towers. It is the first concrete structure of this type in the whole world, designed and erected at the beginning of the $20^{\text {th }}$ century. Because of very bad maintenance during recent decades and due to the absence of roofing, windows and doors, water and moisture have been able to penetrate the concrete surface, causing moisture and frost damage of the concrete. To determine the mineralogical composition of cement stone, an X-ray analysis was performed. Strength analyses were carried out according to EPNENV codes. We can say that most axial and shear forces and bending moments are relatively small. This is the reason why the badly damaged structure has not yet partly or wholly collapsed. The restoration works were begun in autumn 2001 with the central part of the hangar. It was decided to carry out only extremely urgent works.

Keywords: national heritage, residual carrying capacity, restoration.
\end{abstract}




\section{Introduction}

This article reviews the history of the hangars, the results of analyses and measurements made and the needed technical expertise for a restoration project.

Without drawings and other archive material it is difficult to trace down the original material- and constructional solutions. This knowledge would, however, be very valuable in the restoration work and even because the building is very interesting evidence of the early engineering know-how when developing reinforced concrete shells. The material elegance of the structure is astonishing thinking of the technical skills of the time. In some parts the thickness of the shell of the size of $36 \times 36 \mathrm{~m}$ is only $8 \mathrm{~cm}$. It can be regarded almost as a miracle that the clearness, laconism and reliability of the structural solution is still to be perceived although the building looks as if it is on the brink of collapse.

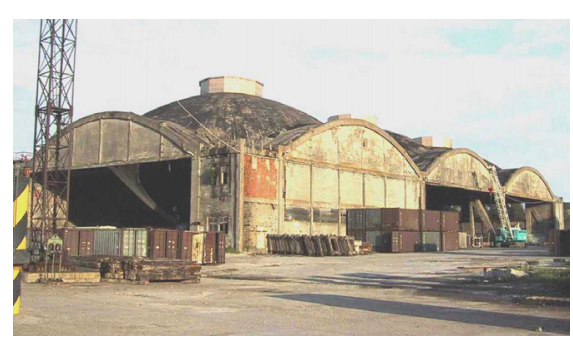

Figure 1: Hangar in Tallinn.

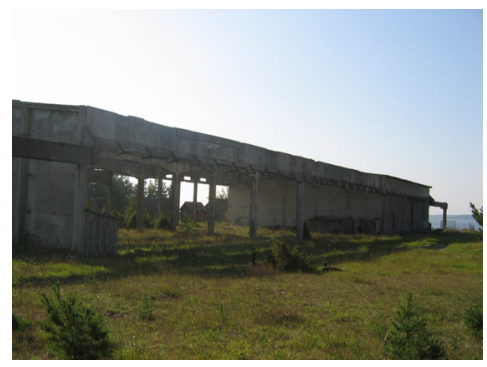

Figure 3: Hangars in Saaremaa.

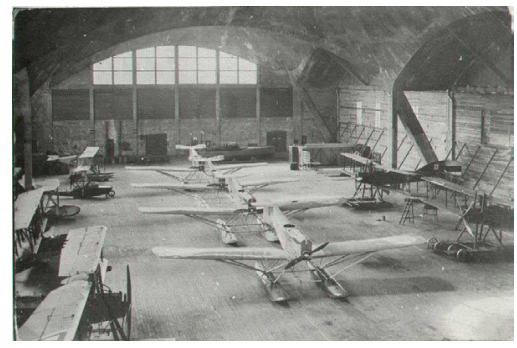

Figure 2: $\quad$ Interior view in 1930.

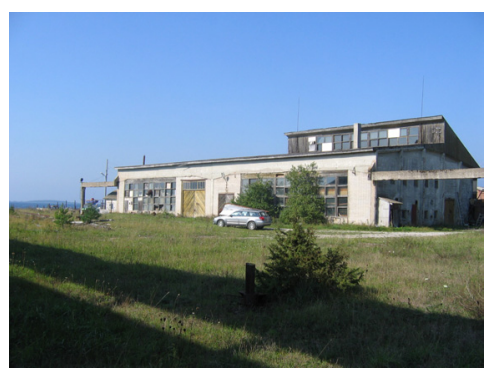

Figure 4: Hangars in Saaremaa.

Local visionists have suggested that the building be used as the Estonian Museum of History of Technology. A recent idea is to locate the submarine "Lembitu" in the building. This would resolve the problem of the Estonian Maritime Museum.

\subsection{History}

In 1907 a defense plan was developed in Russia authorized by the Czar Nicholas II in 1911 according to which a naval operative base had to be built by 1916 . 
The hydroplane hangars are thus one element in a holistic defense/ fortification system for the Baltic Sea area created by Czarist Russia in the first decades of the 1900s - just in advance of the Bolshevist coup d'etat, in the shadow of which the Baltic countries succeeded in restoring themselves among the independent European states.

The projects of both air force bases in Tallinn and in Saaremaa consisted of two groups of hangars - the first had three and the second one two hangars.

The construction of hangars in Saaremaa was completely done.

The construction of hangars in Tallinn started in July 1916 and lasted up till 13 October 1917. Due to the October Revolution in Russia the new Russian government was given an order to terminate the work and finish the contract. By that time the construction of the first group of hangars was practically completed. The erection of the second group of hangars had reached to the point of/as far as the basement.

During 85 years no substantial repairs, which would prolong the lifetime of the reinforced concrete roof shells, were performed. Originally, the upper surface of the hangar shells was covered with a kind of tar paper. Mentions can only be found from the year1938 when the old isolation was scrabbled from the broken places and the concrete cracks were filled with tar. After that the shell was covered with bitumen previously heated to $120^{\circ} \mathrm{C}$. Before lubrication the shell was covered with yellow unbleached cloth. Sand was poured into hot bitumen. The measures concerned only one shell which faces the city. The two remaining shells facing the sea were tarred. In the 1960s all the reinforced concrete roof shells were tarred.

\section{Geometry and design}

\subsection{The hydroplane hangar in Tallinn}

The hydroplane hangar consists of three 36.4 × $36.4 \mathrm{~m}$ in plan reinforced concrete shells and seven short cylindrical shells 36.4 x 6.8 m connected with them. In every corner there are two storey towers $6.8 \times 6.8 \mathrm{~m}$ in plan. At the top of each spherical shell - there is a 12-sided lightning window with the diameter of $10 \mathrm{~m}$. The internal bearing distance is $116.0 \times 36.4 \mathrm{~m}$, the height of the doors is $10.0 \mathrm{~m}$.

The spherical and cylindrical shells interacting are connected. The whole structure is carried by 24 columns and 12 angle braces (columns). The columns are supported on the piled foundation. According to the original project, the piles are connected to a horizontal reinforcement concrete tie beam to receive the horizontal support reaction. More precise data about the quantity, parameters and foundation plate thickness of the reinforcement concrete pile are missing.

The corner towers and wall columns are connected with a horizontal reinforcement concrete beam. Certain parts of load resistance are taken by those walls and columns.

To increase wind load resistance, the reinforcement concrete columns and wall blocks are connected with metal braces. 


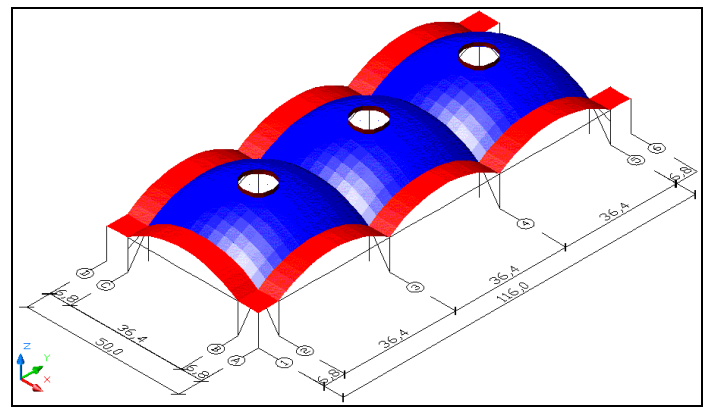

Figure 5: Measurements of hangar.

Lower beams of all cylindrical shells are equipped with two angle braces to receive the horizontal side wind load. Through those angle braces the wind load will be transferred to the edge of the spherical shell. From the west and north side, the cylindrical shells are restricted with fulfilled reinforced concrete girder, east and south side the area between reinforced concrete girder braces are covered with a wood slat. The southern part of the building houses a singlestoried workshop.

From the engineering point of view, the most interesting part of the construction is the reinforced concrete roof shell of the hangars. The height of the shell edge from the floor is $10 \mathrm{~m}$. The maximal height of the spherical shells under the lightening windows is $22 \mathrm{~m}$ (from the floor) and cylindrical shells to the top are $16 \mathrm{~m}$. The maximum raise of spherical shells is $12 \mathrm{~m}$ and cylindrical ones $6 \mathrm{~m}$. Spherical and cylindrical shells have the curvature radius of $30,6 \mathrm{~m}$. The thickness of shells is $80 \ldots 150 \mathrm{~mm}$ (in corner areas $400 \ldots 720 \mathrm{~mm}$ ). The ratio between thickness $\mathrm{t}(\sim 110 \mathrm{~mm})$ and bearing span

$$
\frac{\mathrm{t}}{\mathrm{L}}=\frac{110}{36400}=\frac{1}{331}
$$

would be rather small number in today's terms.

The shells described are thin as can be seen from the ratio

$$
\frac{\mathrm{t}}{R_{\min }}<\frac{1}{20}
$$

where $R_{\min }$ is the curvature radius.

Thickness of external walls is $0.3 \mathrm{~m}$. Cross-section of the column and angle braces is between $0.60-1.30 \mathrm{~m}$.

\subsection{The hydroplane hangars in Saaremaa}

The hydroplane hangar consists of three $22,0 \times 21,8 \mathrm{~m}$ in plan reinforced concrete frames (columns tbeams). The internal bearing distance is $22,0 \times 21,8 \mathrm{~m}$, the height of the doors is $5,15 \mathrm{~m}$. 
The whole structure is carried by 24 columns and 18 beams. The columns are supported on the piled foundation. Cross-section of the columns is $0,30-0,45 \mathrm{~m}$ and beams is between $0.30-1.40 \mathrm{~m}$.

The second hangar consists of two $22,0 \times 21,8 \mathrm{~m}$ concrete frames.

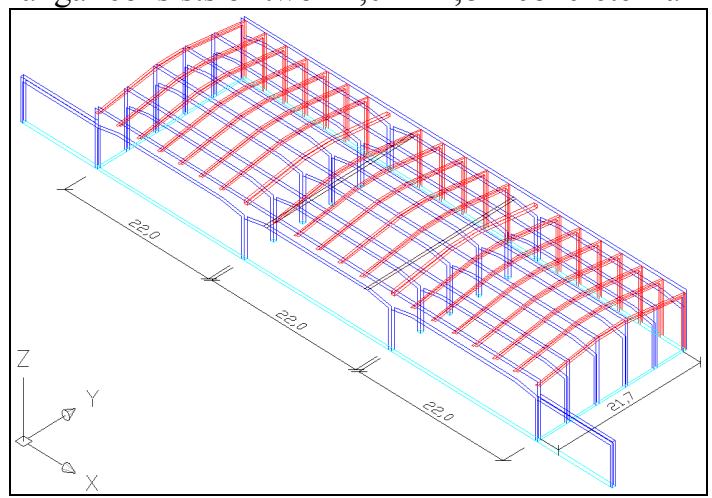

Figure 6: Measurements of hangar.

\section{The technical condition}

\subsection{The shell construction in Tallinn}

Because of very poor maintenance during the last decades and due to the absence of roofing, widows and doors, water and moisture has penetrated in the concrete surface, causing moisture and frost damage of concrete and corrosion of reinforcement and washing out of binder.

In some places corrosion of reinforcement is so extensive that only prints of the corrosion are left. On the lower surface of the shells nearby $50 \%$ of the cover layer is absent and some pieces of concrete cover are continuously falling down.

Due to the missing cover layer and decreasing cross section of reinforcement, the reinforcement does not serve its purpose in receiving the internal forces. The condition of the upper surface of the shells is better, due to the thicker cover layer of concrete.

Extensive damage is seen everywhere (columns, edge elements, diagonals). Because of relatively wide cross-sections, the damage is not dangerous from the point of view of the stress-strain state. Restoration and reinforcement is still necessary.

Central spherical shell has an area of $\left(\sim 6 \mathrm{~m}^{2}\right)$ where part of the shell was broken, settled downward $\sim 70 \mathrm{~mm}$.

The crack between the spherical and cylindrical shells was formed both in the north side and middle shells. The present dangerous situation is reduced on the middle shells.

Many cracks have emerged on the top surface of shells. The total length of the cracks is about $650 \mathrm{~m}$ and most of them pervade the shells. The cracks have been caused by temperature and humidity changes; possibly also by the 
shrinking concrete volume (the $100 \mathrm{~m}$ long construction has no temperature joints).

All three shells have rounded cracks, caused by work-joints originating from the erection.

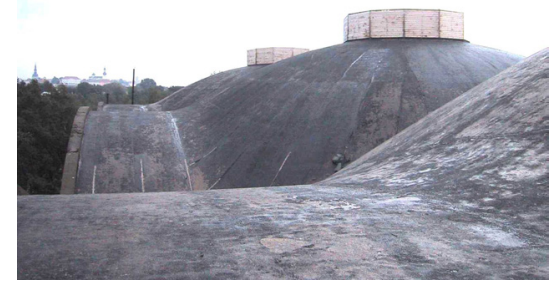

Figure 7: The shell coverage.

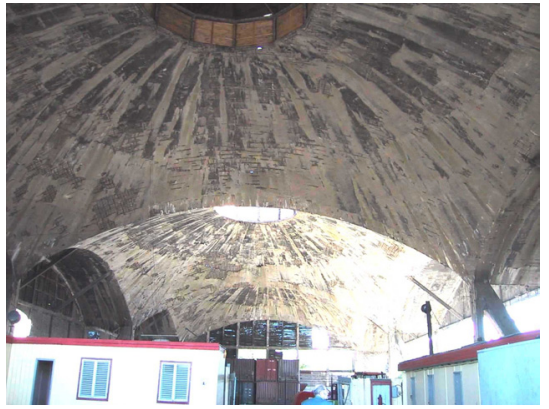

Figure 8: Damage of the lower surface.

Now the upper surface of the shell is covered only partly with oxidized bitumen. Most upper surfaces of the shell have been washed with rain and are cracked. In autumn 2001, the central part of the spherical shell and two cylindrical shells were covered with SBS type roofing.

\subsection{The hangars in Saaremaa}

Damage is seen everywhere (columns, beams). Because of relatively wide crosssections and reinforcement, the damage is not dangerous from the point of view of the stress-strain state. Restoration and reinforcement is still necessary.

The reason for the damage is poor maintenance during the last decades and due to the absence of roofing, widows and doors, water and moisture has penetrated in the concrete surface, causing moisture and frost damage of concrete and corrosion of reinforcement and washing out of binder.

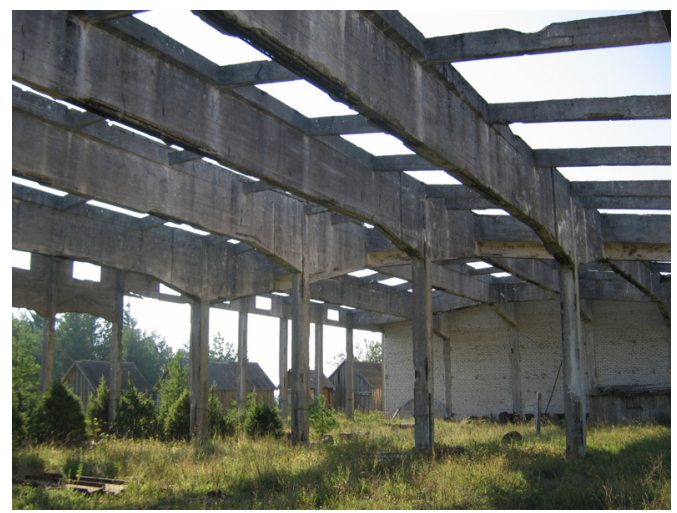

Figure 9: Damage of the hangar frame. 


\section{Material research concerning the reinforced concrete}

In order to analyze the concrete and reinforcement condition, materials research was performed in the Center of Material Research and Testing Laboratory of Building Materials of TUT. During the research the cause, extent and nature of corrosion was determined.

The compression strength of concrete in Tallinn hangar was according to the measurements $10-25 \mathrm{MPa}$ (shells 10-15 MPa, column elements 20-25 MPa).

To determine frost resistance, two cylindrical core samples with the diameter of $90 \mathrm{~mm}$ and depth of 60 and $80 \mathrm{~mm}$ were drilled out. These samples were drilled out exactly in the places, which were repaired by stitching dogs and glued cracks. The frost resistance was determined according to standard GOST 1006087 - i.e. the number of frost cycles, where the mass loss does not exceed $3 \%$ of the initial mass. The mass loss of 3\% was formed in the case of the first sample having 110 (F110) frost cycles and the second sample having 150 (F150) frost cycles. The mark F150 is comparable to Estonian standard "The frost resistance of normal concrete" level KK3 (highest required level is KK4).

To determine the mineralogical composition of cement stone, an X-ray analysis was performed. The X-ray analysis helps to determine the existence and amount of substances, which have crystal structure. The samples of concrete were taken from the depth of 40-50 mm. For research purposes the samples were concentrated $50 \%$ in relation to cement stone. This means that the sample was smashed in a muller and the amorphous part was milled out. In the sample, no crystal substance, containing sulphate was identified. According to the result of the X-ray analysis, the content of chloride in cement stone is less than $0.5 \%$ and the content of etringit is less than $3 \%$.

The carbonation depth can be determined by the content of $\mathrm{CaCO}_{3}$. In this case it was not possible, because concrete, which contained limestone was used for the erection of hangars. The only possibility to measure the carbonation depth is by the content of $\mathrm{Ca}(\mathrm{OH})_{2}$. To determine the content of $\mathrm{Ca}(\mathrm{OH})_{2}$ the above mentioned X-ray analysis was used. According to the results, the ratio of the amount of $\mathrm{Ca}(\mathrm{OH})_{2}$ in cement stone to the $\mathrm{CaCO}_{3}$ was determined by expert opinion (based on experience). The analysis results were used for (checked through a) comparison. The samples for this were taken from dock concrete of Tallinn Kopli Port, as Kopli Port has similar environmental conditions. The concrete of Kopli Port had carbonation depth of 20-30 mm. According to the calculations, the highest content of $\mathrm{Ca}(\mathrm{OH})_{2}$ in relation to $\mathrm{CaCO}_{3}$ is $38.9 \%$. In the case of the hydroplane hangars, the corresponding ratio was $35.4 \%$.

So, it is possible to conclude that the concrete of the hydroplane hangars shells is carbonated throughout the cross-section.

In addition, the porosity of concrete (water absorbent test) and the morphology of the fracture of concrete were measured. The porosity was determined by the absorption of the sample in relation to dry material mass and absorption speed.

Water absorption was determined according to the standard DIN 52 103. The evaluation is based on the expert opinion (experience based), because no 
valuation standards to measure the percent absorption of concrete or the porosity caused by absorption are available. For comparison purpose, the absorption of concrete from the Helsinki Olympic Stadium, built about the same decade (in the 1930s), was taken. Most obviously, the technology and the components of this concrete had characteristics similar to those of the hydroplane hangars. According to the research the absorption of the hydroplane hangar concrete is $2,5 \%$ greater than that of the concrete of the Helsinki Olympic Stadium and the average rate of absorption is 32 times greater. So, concrete in the hangar has a high porosity.

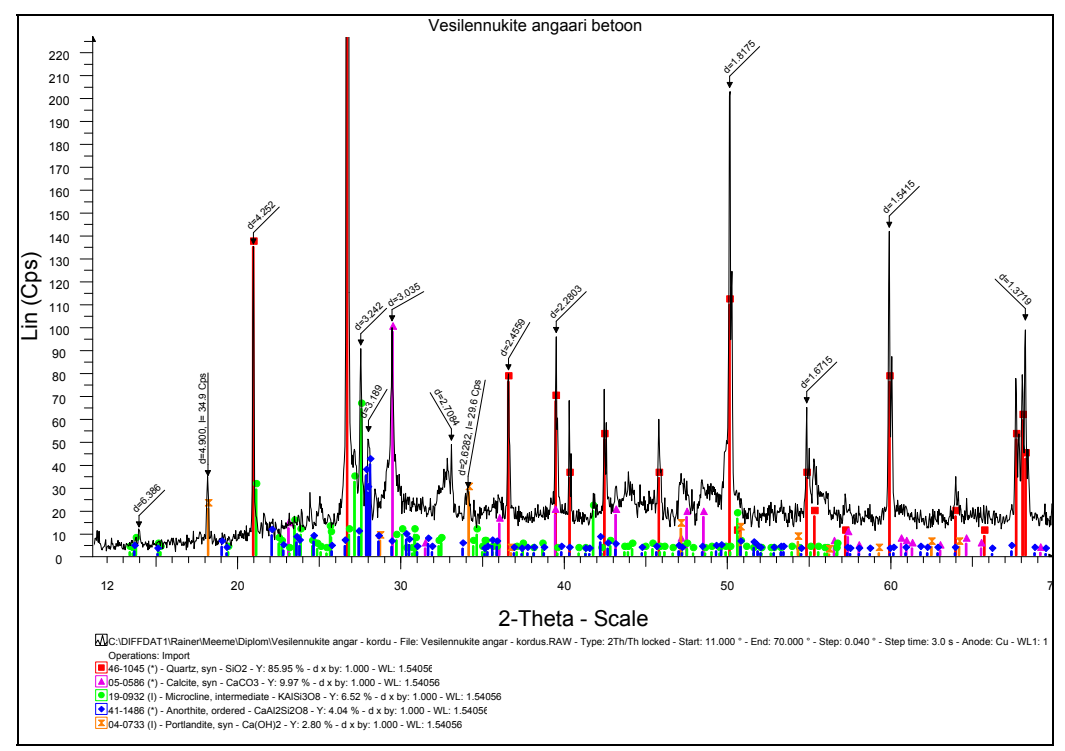

Figure 10: Diffractogram of X-ray analysis.

To determine the existence of substances, which have crystal and amorphous structure in concrete, the morphology of concrete facture was studied with scanning electro-microscope. These analyses confirmed the result of the X-ray analyses about the mineralogical composition of cement stone. Also, on the bases of the photos made, the structure of concrete can be considered as porous.

The core sample, which was drilled out, shows that the diameter of reinforcement bar is $8 \ldots 10 \mathrm{~mm}$, edge elements and columns are ca $25 \mathrm{~mm}$. The spacing of the upper reinforcement bars and the lower reinforcement bars is $\sim 200 \times 200 \mathrm{~mm}$. According to the test, the medium yielding point of reinforcement is $f_{y}=288.6 \mathrm{MPa}$, and tension strength $f_{u}=407.2 \mathrm{MPa}$. Reinforcement bars are parallel to the shell edges. The diagonal reinforcement (for receiving the tension stress) in the corners of the spherical shells is absent.

The material research confirms that the cause of concrete damage was the absence of roofing. Due to the concrete had its binder washed out. The evidence of binder-washed out corrosion on the lower surface of shells is a white substance $\left(\mathrm{CaCO}_{3}\right)$ and stalactite. Due to the above-mentioned reasons, the 
cement stone was decomposed, the porosity of concrete was increased, the carbonization process was fastened and so the reinforcement was corroded and the cover layer of concrete was lost.

The average compression strength of concrete in Saaremaa hangars is 22,0 Mpa. According to the test, the medium yielding point of reinforcement is $f_{y}=$ 251,6 MPa, and tension strength $f_{u}=290,8 \mathrm{MPa}$.

Concrete of the hydroplane hangars in Saaremaa is carbonated throughout the cross-section.

However, the characteristics of the both concrete and reinforcement are still sufficient in order to restore the hangars in Saaremaa and Tallinn.

\section{Numerical analysis of the stress and strain state}

No complicated calculations, in today's terms, were made during the erection process of the hangars. The shells and frames were designed by simple calculation methods. Unfortunately, the strength and static calculations have not preserved. So, it makes it very interesting to see the calculation results made by help of contemporary equipment and knowledge and to see whether those results conform to the concepts and engineering instinct of the1920s.

The stress and strain state calculations of shell constructions were carried out using the FEM (Finite Element Method) according to Staad/Pro (hangar in Tallinn) and Robot Millennium (hangars in Saaremaa).

\subsection{Initial data}

The self weight load of the shells was calculated according to the measured geometry and according to the additional load foreseen in the restoration project. Snow, wind and self weight load was determined according to EPN-ENV Standard, taking into account various combinations of loads. The internal forces of reinforcement concrete modulus of elasticity were calculated, based on $25 \mathrm{KN} / \mathrm{mm}^{2}$ and Poisson figure 0.17 .

\subsection{Strength analyses}

The initial data for strength analyses were characteristics of materials, main working principles of hangar constructions and internal forces determined by the stress-strain state.

Additionally, technical conditions (damage) were taken into consideration. The strength analysis was carried out according to EPN-ENV codes.

\subsection{The results of the calculations}

Based on the analysis of the stress-strain state, a conclusion can be drawn that most axial and shear forces and bending moments are relatively small. It is the reason why the badly damaged structure has not partly or wholly collapsed.

At the same time it is necessary to underline that to perform in all areas of the shells, the stress analysis is quite impossible, because the initial data is inaccurate and the remaining reinforcement, the concrete strength and 
functioning cross-section are variable. Only overall estimation can be given according the data of some areas.

To summarize we can say that the Danish engineers have very wisely chosen the geometry of shells and cross-sections of elements. There is still something contemporary engineers can learn from Danish engineers.

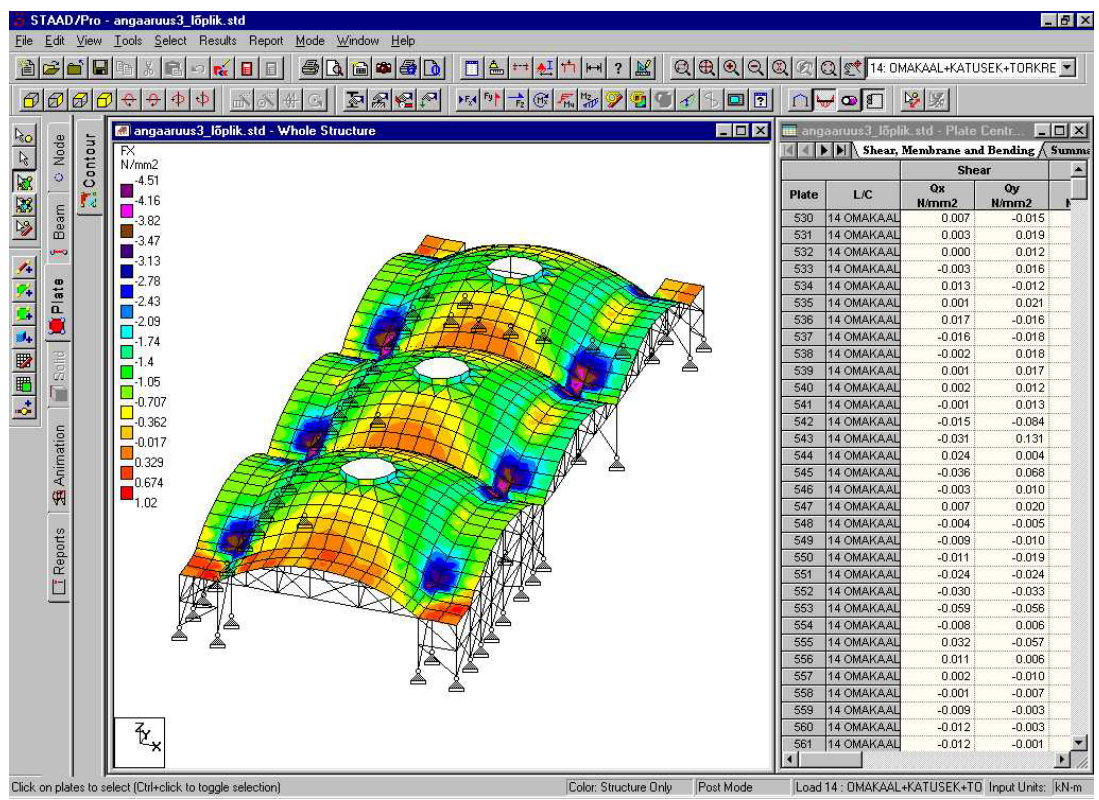

Figure 11: Calculation scheme in Staad/Pro.

\section{Restoration efforts}

So far it has not been possible to perform a complete restoration of the hydroplane hangars in Tallinn. In the autumn of 2001, the restoration process started with the middle shell, because that shell was in the worst condition, but only inevitable repairs were carried out then. Taking into account the financial possibilities it was decided to repair the area settled down by stitching cracks, gluing the cracks with epoxy resin and by installing roof coverage.

The area of the spherical shell, which was settled down and shifted, was reinforced with reinforcement Bp-I Ø $3 \mathrm{~mm}$ and $\varnothing 5 \mathrm{~mm}$, with spacing $100 \mathrm{~mm}$. Reinforcement bars-anchor were fixed to canals, which were milled from one side and fixed from the other side to drilled holes with a glue mixture. Then the shell, previously from old damaged roof coverage, was covered with bond varnish and monolithed with special mortar. In the same way - the monoliththing of the crack-hole of joint cylindrical and spherical shell was reinforced.

Before stitching and injection, the cracks were cleaned and treated with biological repellent. Then the cracks were covered with bond varnish. Reinforcement anchors Bp-I Ø $5 \mathrm{~mm}$ were fixed to canals with spacing $250 \mathrm{~mm}$. 
Reinforcement anchors_were milled on one side and fixed on other side to the drilled holes with glue mixture. Then the cracks were injected with epoxy resin.

Before covering the shells with the SBS type roof covering, the old bitumen was scratched out and the fogged areas were treated with a biological repellent. The cleaned shells were covered with bond varnish. The new SBS type roof cover had two layers; it was armed with polyester fiber and covered with bulk. The roof covering was fixed additionally from edges with rivets (spacing $0.5 \mathrm{~m}$ ) in the parts of shell, which had larger incline and window lighting surroundings. Additionally, the water drain system was repaired and new pipes were installed. The edge elements of the cylindrical shells were rimmed with sheet metal.

\section{Conclusion}

We can conclude that the damage of concrete and reinforcement were caused by very poor maintenance in the unclear owner situation during the last decades. Binder was washed out - white substance $\left(\mathrm{CaCO}_{3}\right)$ and stalactite on the lower surface of shells. The cement stone was decomposed, the porosity of concrete was increased, the carbonization process was fastened and so the reinforcement was corroded and the cover layer of concrete was lost.

According to the analysis we can say that mostly axial and shear forces and bending moments are relatively small. Because of relatively wide cross-sections, the damage is not dangerous from the point of view of the stress-strain state.

It is the reason that badly damaged structures has not partly or wholly collapsed till this time. Restoration and reinforcement is still necessary.

According to the results of the analysis, a restoration solution was developed for the hangar in Tallinn. A proper restoration and strengthening is very costly. At the same time a substantial increase in the carrying capacity and reliability of the structures can be achieved. It is, however, necessary to continue the pending works: to reinforce the cracks of two side shells, by reinforcement and gluing, to monolith the holes and install roof coverage. Then, the lower shell surface has to be cleaned. For that, the crumbling concrete has to be removed from the concrete columns, diagonals, walls and braces. If necessary, the new strengthening reinforcement (better stainless) will be added and then the external surface will be covered by two- or three layer sprayed concrete (shot plaster).

If the above mentioned urgent measures are delayed for some more years, the restoration and preservation of the Hydroplane Hangars in Tallinn will be questionable or hardly feasible.

\section{References}

[1] P. I Tunturi, Korroosio käsikirja, Suomen Korrosiooyhdistus, Hanko 1988

[2] H. Laul, Raudbetoon II, Tallinn 1962

[3] A. M. Neville, J. J Brooks, Concrete Technology, UK 1987

[4] A. M. Neville, Properties of Concrete, UK

[5] Aberdeen's Concrete Construction magazine, Concrete Repair, Volume 3, 1988, Reprinted March 1993 